\title{
Multiple positive solutions for four-point boundary condition of fractional delay differential equations with p-Laplacian operator
}

Shuai $\mathrm{Li}^{1}$, zhixin zhang ${ }^{1}$, and Wei Jiang ${ }^{1}$

${ }^{1}$ Anhui University

June 27, 2020

\begin{abstract}
In this work, a class of fractional delay differential equations with four-point boundary condition and p-Laplacian operator are discussed. Based on the Avery-Peterson theorem, the existence of at least triple positive solutions are derived. An simple example are given to show the validity of the conditions of our main theorem.
\end{abstract}

\section{Hosted file}

Main Document.pdf available at https://authorea.com/users/337346/articles/462943-multiplepositive-solutions-for-four-point-boundary-condition-of-fractional-delay-differentialequations-with-p-laplacian-operator 